\title{
Investigating the impacts of personality on the use and perceptions of online collaborative platforms in higher education
}

\author{
Meghan E. Borg ${ }^{1}$ (D) Kaitlyn M. Butterfield ${ }^{1} \cdot$ Eileen Wood $^{1}$. \\ Huan Huan Zhang ${ }^{1}$. Sabrina Pinto ${ }^{1}$
}

Received: 15 September 2020 / Accepted: 23 December 2020 / Published online: 1 February 2021

(c) The Author(s), under exclusive licence to Springer Nature Switzerland AG part of Springer Nature 2021

\begin{abstract}
Collaborative work is a critical component of active learning. Where in-person collaboration may not be possible, inclusion of online collaboration tools has become more prevalent. Previous studies have suggested that online collaboration is beneficial to overall learning outcomes; however, little research has investigated how differences in personality traits, such as extraversion and agreeableness, impact the benefits and effectiveness of collaborative learning, both through online (synchronous and asynchronous) and in-person platforms. In the present study, $360(66.4 \%$ female) undergraduate students completed an online survey to assess perceptions of and beliefs about online synchronous, online asynchronous, and in-person collaboration in higher education with a focus on the impact of extraversion and agreeableness. Findings indicated that students had more experience and greater preference for online synchronous collaboration compared to online asynchronous collaboration; however, students believed that in-person collaboration was most effective. Both extraversion and agreeableness predicted positive beliefs about group work in both online and in-person settings but not uniformly. These findings support the use of online synchronous collaboration when in-person opportunities are limited; however, individual differences related to personality traits can differentially impact students' perceptions toward and actions within collaboration contexts.
\end{abstract}

Keywords Collaboration · Higher education · Online synchronous · Online asynchronous · Extraversion · Agreeableness

Meghan E. Borg

borg7410@mylaurier.ca

1 Department of Psychology, Wilfrid Laurier University, 75 University Ave W, Waterloo, ON N2L 3C5, Canada 


\section{Introduction}

Collaborative work is a critical component of active learning both outside and inside the classroom (Kieser and Ortiz Golden 2009). Collaboration involves synchronized learner activity that is incorporated to create and maintain a collectively shared outcome (Alluri and Balasubramanian 2002). Benefits associated with collaborative learning include engaging students in the dynamics of being a team player and working with others, promoting active learning, as well as developing critical thinking and social skills (Felder and Brent 2001; Kieser and Ortiz Golden 2009; McInnerney and Roberts 2004). Well-constructed collaborative learning environments accommodate students with differing learning styles which can increase attention and participation as well as generate stronger student-teacher relations (Kieser and Ortiz Golden 2009).

Early research on collaborative learning in higher education contexts evaluated face-to-face discussions and interactions (e.g., Mahoney and Harris-Reeves 2019; Johnson and Johnson 1989); however, the growth in the number and sophistication of online platforms has expanded the opportunities to integrate collaborative group work as part of ongoing instructional design. The use of technology permits synchronous or asynchronous collaboration within and beyond the classroom. These additions have expanded the contexts and timing for how learners can meet and exchange ideas. As a result, there are increased opportunities for instructionally relevant cooperation and learning for students, especially in higher education contexts (e.g., Siqin et al. 2015). Online learning can provide students with the opportunity to flexibly engage in course material. For example, a recent study by Nieuwoudt (2020) found that participating in synchronous virtual classes or watching recorded classes did not predict increased academic success. Thus, for students in higher education who may struggle to balance school, work, and other obligations, online learning may serve as an effective tool for learning.

As technology and the Internet have become integral instructional and learning tools in the classroom (Carrier et al. 2015; Sung et al. 2016), there has been a parallel increase in the use of online collaboration tools. One common online collaboration platform, Google Docs developed by Google Inc, allows users to synchronously or asynchronously create, collaborate, and edit the same document over the Internet (e.g., Shahabadi and Uplane 2015). This flexibility permits opportunities for both immediate feedback and engagement as revisions are seen by all users who have access to the shared document, as well as delayed interactions which flexibly accommodate students who differ in school, work, and other life obligations. In this way, synchronous online platforms can mimic the benefits of immediate 'real-time' interactions that are typically associated with in-person collaborations with the added benefit of inclusion for those who cannot meet inperson requirements (e.g., Shahabadi and Uplane 2015). For these reasons, online platforms have served as a valuable way to conveniently connect students and facilitate learning.

Despite previous literature on these various online and traditional platforms, little research has been dedicated to understanding how differences in personality 
traits affect preferences for and outcomes when using these various platforms and instructional contexts. Understanding whether individual differences in personality, specifically the degree of extraversion measured by the Big Five Inventory (Costa and McCrae 1992), is related to university students' perception of collaborative work in general, as well as their preference between online (synchronous and asynchronous) and in-person methods of collaboration can provide insight into the effectiveness of online and in-person collaboration, and how beneficial synchronicity is in facilitating learning.

\section{Collaborative learning in higher education}

Collaborative learning is an educational approach that involves learning in a social environment where intellectual and meaningful discourses happen between learners (Smith and MacGregor 1992). According to the social constructivism framework, knowledge is constructed through social interactions and discussions (Vygotsky 1978). Proponents of this framework (e.g., Bruffee 1986) emphasize the importance of collaboration in the learning process and argue that social interaction is the driving force underlying individuals' cognitive development. During social interactions, learners can internalize ideas they encounter in their social surroundings (Nyikos and Hashimoto 1997). As a result, students who engage in collaborative work, especially with knowledgeable others, become capable of performing at higher intellectual levels than when they work on their own (Gokhale 1995). In addition, social learning theory posits that opportunities to observe modeled behaviors can enhance acquisition of behaviors in the observer (Bandura 1978; Bandura and Walters 1977). Similar to the constructivist frameworks, social learning theory emphasizes the importance of social interactions and environments for shaping learning and acquiring knowledge in a collaborative setting (Lin et al. 2016).

Gains in academic, social, and psychological measures are associated with collaborative learning (Laal and Ghodsi 2012). In an early study, Johnson and Johnson (1989) demonstrated that students who worked collaboratively in teams achieved higher levels of thought and longer retention of information than those who worked individually. Gokhale (1995) also demonstrated higher critical thinking skills among students that worked in collaborative settings. In addition to academic skills, undergraduate students who worked in groups reported higher ratings for motivation, perception of skill development, and solution satisfaction than those who worked alone (Hiltz and Benbunan-Fich 1997). Additionally, collaborative learning helps students develop a healthy social support system through social interactions (Cohen and Wills 1985), which is one of the pillars of collaborative learning according to social constructivist theories.

\section{Technology and collaborative platforms}

Higher education institutions have been experiencing an ongoing digital transformation that includes the summation of digital processes that allows higher education institutions to use and apply digital technologies optimally and effectively (Kopp 
et al. 2019). According to a recent survey conducted by the Canadian Digital Learning Research Association (Johnson 2019), online course registrations rose by $10 \%$ between 2016 and 2017, and 76\% of post-secondary institutions in Canada offered some form of online learning in 2018. Technology has played a major role in collaborative learning, both online and offline. In today's society, students in higher education contexts are less likely to meet face-to-face for collaborative work due to the convenience of communicating and working through emails, instant messaging, discussion forums, and other web-based tools (Koch 2010). This has become heightened due to instructional shifts associated with the COVID-19 pandemic, which has forced higher education institutions to rapidly transition from in-person to wholly online models (e.g., Babatunde Adedoyin and Soykan 2020). Thus, understanding the benefits and limitations of online learning is necessary to understand how this abrupt shift to online teaching platforms contributes to students' learning experiences and outcomes.

Empirical studies have shown that the use of technology in these higher education collaboration contexts enhances learning outcomes and develops higher order thinking skills (e.g., Gokhale 1995; Resta and Laferrière 2007). Early research established that the introduction of computer-supported learning methods yielded higher quantity and quality of daily outputs and greater mastery of factual information than individual learning (Johnson and Johnson 1989). Students who engaged in collaborative learning using a technology-based support system obtained higher grades than those who did not (Alavi 1994). More recent research indicates that when compared to traditional in-person collaboration, students who experienced an online collaborative environment reported higher learning and were engaged in more advanced and challenging cognitive discussions (Benbunan-Fich et al. 2003). Moreover, studies have found that online applications enhance collaboration, help with collaborative writing, and facilitate the development of social skills, teamwork, and computing skills (Apple et al. 2011; Koch 2010; Zhou et al. 2012).

Technology allows for various methods of asynchronous and synchronous collaboration among learners. Online synchronous collaborative platforms allow users to create and edit documents at the same time. Examples of online synchronous platforms include office suites by Google (e.g., Google Docs, Google Slides, and Google Sheets), Prezi, and Wikis (shared writing space online that is typically focused around a specific topic and can include text, images, and videos; Knobel and Lankshear 2009; Sharp and Whaley 2018). In contrast, asynchronous online collaborative platforms involve collaboration in settings where discussions are not exchanged instantly with other parties. Examples of such platforms may include discussion forums and emails where participants send messages or submit posts and the receiving parties may review and respond to them when they receive them or at later times.

Asynchronous online sharing of a document through in-person group work or through platforms such as email or messenger requires the distribution of multiple copies among other members of the group, which may be less efficient given the need to consolidate feedback from multiple editors or the lag in time if sequential editing across group members is required. These platforms, however, may reduce demands for face-to-face social interaction and less social interaction overall, 
placing less emphasis on social abilities which may be advantageous for some learners (Lomas et al. 2008). Research indicates that the use of an online collaborative platform, such as Google Docs, resulted in significantly higher scores on a writing task compared to use of a traditional collaborative method, such as in-person meetings (Suwantarathip and Wichadee 2014). These initial outcomes suggest that online synchronous platforms may promote greater learning and engagement among students than asynchronous methods. Although past research suggests that online platforms are beneficial to overall learning outcomes, it is necessary to understand how these platforms impact different learners, and how individual differences in personality traits, such as extraversion, impact the effectiveness and use of collaborative learning.

\section{Extraversion and general collaborative work in higher education}

Effective collaboration typically requires social interaction, and thus social skills are an important consideration in most collaborative learning contexts (Johnson et al. 1984). As noted earlier, social learning theory and social constructivist theories of learning (Vygotsky 1978; Bandura 1978; Bruffee 1986) highlight the importance of social contexts consistent with collaborative contexts as a vehicle for learning. However, individual differences may impact how learners approach and function in collaborative group contexts and this, in turn, has the potential to impact what they learn and how much they learn. According to the Five Factor Model (Costa and McCrae 1992), a hierarchical model of personality traits, a core feature of the bipolar factor of extraversion vs. introversion embodies the tendency to engage in social behaviors (Revelle and Wilt 2008). Specifically, the extraversion-introversion factor measures individuals' level of warmth, gregariousness, assertiveness, activity, excitement seeking, and positive emotion.

Significant research has examined the relationship between personality and teamwork (e.g., Driskell et al. 2006; Barrick et al. 2001). Past studies indicate that those high in extraversion tend to feel more confident about their ability to perform in a group setting compared to those who score high on introversion (Barry and Stewart 1997; Thoms et al. 1996; Walker 2007). In addition, those high in extraversion are often seen as having contributed more to the group outcome by others (Barry and Stewart 1997). Moreover, French and Kottke (2013) found group members with high extraversion scores reported higher satisfaction for teamwork than those with lower extraversion scores. While those high in extraversion typically enjoy group work and the social stimulation that arises from collaboration, high academic achievements on group projects are not always positively related with high extraversion. Within the context of education, not all students enjoy or benefit from working in groups (Colbeck et al. 2000; Walker 2007). Introverts' success in higher education has been attributed to other factors such as their individual ability to consolidate learning (Entwistle and Entwistle 1970; Furnham et al. 2003). Thus, the extraversion-introversion trait is strongly linked to students' learning experience and extraversion may be particularly salient in the collaborative work context. 
Recently, studies of personality have shifted focus to examine the relationship between extraversion and technology-supported group work in various settings. Theoretically, extraverts may be at a disadvantage compared to introverts in distance learning courses facilitated by web-based platforms because they lack the social stimulation and may feel more isolated in these online environments (e.g., Myers and McCaulley 1985). However, the absence of the need for faceto-face interactions provides the opportunity for introverts to share their ideas on "an equal footing" with extraverts (Voorn and Kommers 2013). While extraverts perceive social and face-to-face interactions as positive stimulus, introverts are more attracted to online collaborations than extraverts because of the lack of such intimidating features of face-to-face communications (Goby 2006; Myers and McCaulley 1985). Amichai-Hamburger et al. (2004) suggested that introverts prefer online platforms more than extraverts because these platforms provide opportunities to find their "real self". Not surprisingly, therefore, online learning environments relate to higher achievement more so for introverts than extraverts (Offir et al. 2007).

In addition to personality traits measured by the extraversion-introversion dimension, group work could also be facilitated by another trait of the Five Factor Model: agreeableness (Costa and McCrae 1992). Agreeable individuals tend to be pleasant and cooperative in social situations. Farsides and Woodfield (2003) suggested that individuals with high agreeableness would thrive in collaborative social interaction settings. In fact, past literature has demonstrated that agreeableness is a strong predictor of overall performance in various team settings (Mount et al. 1998; Barrick et al. 2003; Bell 2007). A recent study by Bradley et al. (2013) studied project teams consisting of five undergraduate students. Researchers found that though highly agreeable teams had better communication and performance when interacting face-to-face, low agreeableness teams performed similarly when interacting virtually. This study provides evidence that agreeableness is important in team settings; however, little research has been dedicated to investigating differences between extraversion and agreeableness as they relate to various methods of collaborative group work in higher education.

\section{Current study}

The general objective of the current study was to understand first-year university students' general perceptions and experiences with both synchronous and asynchronous collaboration. Thus, this study contributes to higher education literature regarding the relative impact of online synchronous and asynchronous platforms and in-person collaborations on students' perceptions regarding the platforms, how collaborative platforms impact learning, and how individual differences in students' levels of extraversion/introversion and agreeableness predict preferences of and experiences with these collaborative platforms. Five hypotheses were generated based on past research: 
(1) Students will have some experience using both online collaborative platforms (both synchronous and asynchronous) as well as in-person collaboration for academic group work.

(2) Overall, students will prefer the effectiveness of online synchronous collaboration to both online asynchronous collaboration and in-person collaboration.

(3) Extraversion and agreeableness will predict higher preference for group work.

(4) Extraversion and agreeableness will predict higher belief that in-person collaboration is easier to use compared to online synchronous collaboration.

(5) Higher extraversion and agreeableness scores will be associated with participants' ratings regarding perceived impact to social skills when using in-person collaboration compared to online synchronous collaboration.

In addition to these hypotheses, given the limited literature regarding collaboration employing various technologies, the present study also provided an opportunity to explore students' perceptions of group work and technology-based platforms in higher education.

\section{Method}

\section{Participants}

A sample of 360 first-year undergraduate students (66.4\% female) were recruited through a university psychology participant pool at a mid-sized Canadian university. Ages ranged from 17 to 36 years of age $(M=18.33, \mathrm{SD}=1.30)$. There were no significant age differences as a function of gender, $t(357)=0.26, p=0.608$. Participants primarily identified as White $(57.8 \%)$ or Asian $(20.6 \%)$ with remaining participants identifying as other (9.7\%), European (5.8\%), Black/African American (5\%), French Canadian (0.6\%), and Aboriginal/First Nations/Inuit (0.6\%). Overall, $38.7 \%$ of participants were pursuing a Bachelor of Arts degree $(n=138), 28.9 \%$ were pursuing a Bachelor of Science degree $(n=103), 27.7 \%$ were pursuing a combination degree $(n=99)$, and $4.8 \%$ were pursuing a specialized degree (e.g., Bachelor of Kinesiology; $n=17$ ). Overall, participants' self-rating of comfort with technology approached ceiling on a 5 -point Likert scale $(M=4.32, \mathrm{SD}=0.86 ; 5=$ very comfortable).

This project was reviewed and approved by a University research ethics board. Participants received partial course credit or were entered to win a draw prize as remuneration for participation. All participants were treated according to ethical standards of APA/CPA.

\section{Materials and procedure}

All participants individually completed one online survey while in a group setting in a university classroom. Completion of the survey took approximately 15-20 min; however, participants were given as much time as needed to complete the survey. 
One research assistant was present during all testing sessions to supervise and provide technical assistance if necessary.

\section{Survey}

The survey was comprised of five main subsections: demographics (i.e., gender, age, program of study, ethnicity), extraversion and agreeableness, group dynamics, experiences with and perceptions of collaborative platforms, and experiences with and perceptions of group work in an academic context.

\section{Extraversion and agreeableness}

Extraversion and agreeableness scores were calculated from the 8-item and 9-item subscales from the Big Five Inventory (Costa and McCrae 1992; John and Srivastava 1999). The extraversion vs. introversion subscale included statements that described gregariousness, assertiveness, activity, excitement seeking, positive emotions, and warmth, with a maximum score of 40. The agreeableness subscale included statements that described trust, straightforwardness, altruism, compliance, modesty, and tender-mindedness, and had a maximum score of 45. Participants rated how much they agreed that each characteristic applied to them using a 5-point Likert scale ( $1=$ disagree strongly to $5=$ agree strongly). Cronbach's alpha was 0.82 for extraversion, and 0.71 for agreeableness, indicating acceptable internal consistency.

\section{Group dynamics}

Sixteen questions assessed group dynamics in a university setting. Participants were asked to answer questions based on personal group work experiences on projects that resulted in the formal submission of a university assignment. Participants indicated their preferred group dynamic from three categorical responses $(1=I$ prefer to work on my own more than I prefer to work in a group, $2=$ I prefer to work sometimes in a group and sometimes on my own, and 3=I prefer to work in a group more than I prefer to work on my own). Three additional questions measured group formation, each using 5-point scales (anchors $1=$ almost never to 5=always), and included how often groups were randomly formed by the instructor; how often participants actively sought group members who were classmates and/or friends that were familiar to them; and how often participants actively sought classmates who were unfamiliar to them to do assigned group work. Participants indicated how satisfied they were with each selection method using a 5-point scale $(1=$ very unsatisfied to $5=$ very satisfied). Preferred group size was assessed through one question with four categorical responses $(1=$ myself and one other person, $2=$ myself and two others, $3=$ myself and three others, and 4=myself and four or more others). Perceptions regarding five aspects of group work (i.e., perceived workload, efficiency, motivation, stress, and satisfaction) were rated using a 5 -point scale $(1=$ not at all to $5=$ extremely). 


\section{Experience with and perceptions of collaborative platforms}

Seven questions assessed experiences with and perceptions of online collaborative platforms. Participants rated their comfort with using computer technology on a 5-point scale $(1=$ very uncomfortable to $5=$ very comfortable $)$. Participants also rated their familiarity (i.e., $1=$ not at all familiar to 5=extremely familiar) with four online synchronous collaborative platforms (i.e., Google Docs, Google Slides, Prezi, and Google+ platforms) and two online asynchronous collaborative platforms (i.e., email, and discussion forums/Facebook groups/Google communities/Stack Exchange).

Frequency with in-person collaboration (i.e., in-person meetings), online synchronous collaboration (e.g., instant messaging), and online asynchronous collaboration (i.e., email) and contributing ideas to group discussions in each context were assessed using 5-point scales $(1=$ almost never to $5=$ always $)$. Participants rated the overall effectiveness of group work in each context using a 5-point scale ( 1 = extremely ineffective to $5=$ extremely effective).

To effectively compare in-person collaboration to online synchronous collaboration, participants were asked questions to directly compare these two platforms. Participants rated how difficult generating a final output for a group assignment was when using in-person collaboration compared to online synchronous collaboration on a 5-point scale $(1=$ always more difficult when using in-person collaboration than online synchronous collaboration to $5=$ always easier when using in-person collaboration than online synchronous collaboration), and how they would compare their learning experience from group assignments when using in-person collaboration compared to online synchronous collaboration $(1=$ always much worse when using in-person collaboration than online synchronous collaboration to $5=$ always much better when using in-person collaboration than online synchronous collaboration). Participants also rated how their personal social skills were impacted when using both in-person collaboration and online synchronous collaboration on a 5 -point scale ( $1=$ very negatively to $5=$ very positively).

\section{Data analysis and interpretation}

Analyses were conducted using the Statistical Package for the Social Sciences (SPSS), version 26. Analyses of variance (ANOVA) were used to assess group differences and linear regressions were used to predict outcomes related to methods of group work as a function of extraversion and agreeableness. The level of significance was set at $p \leq 0.05$ for all analyses. 


\section{Results}

\section{Extraversion and agreeableness}

Overall, mean levels of extraversion $(M=26.42, \mathrm{SD}=5.70$; maximum $=40)$ and agreeableness $(M=34.69, \mathrm{SD}=4.81$; maximum $=45)$ were above the midpoint of the scales. A one-way ANOVA comparing participants as a function of area of study revealed no significant differences between type of university degree (BA, BSc, Combination, and Other) and either extraversion, $F(3,353)=1.64$, $p=0.178$, or agreeableness $F(3,353)=0.58, p=0.626$.

\section{Familiarity with technologies}

Given the emphasis on in-person versus technology-based collaboration methods, it was important to establish general comfort and familiarity with technology and collaboration tools. Overall, participants reported high levels of comfort using computer technology in general $(M=4.23, \mathrm{SD}=0.86)$, as well as high familiarity for online collaboration tools such as Google Docs $(M=4.43, \mathrm{SD}=0.89)$, Google Slides $(M=4.03, \mathrm{SD}=1.26)$, and Prezi $(M=3.10, \mathrm{SD}=1.28)$ and some familiarity with Google+ platforms $(M=2.47, \mathrm{SD}=1.33)$.

\section{Experience with in-person and online collaboration}

All forms of collaboration were used by at least some participants. However, participants rarely used online asynchronous collaboration such as email $(M=1.84$, $\mathrm{SD}=0.98$ ) or discussion forums/Facebook groups/Google communities/Reddit, Stack Exchange, etc., $(M=2.19, \mathrm{SD}=1.31)$. To determine relative frequency of use among in-person and both online types of collaboration (hypothesis 1), a oneway repeated measures ANOVA was conducted comparing in-person collaboration (i.e., in-person meetings), online synchronous collaboration (i.e., instant messaging), and online asynchronous collaboration (i.e., email) when communicating with group members. The ANOVA violated Mauchly's sphericity, $\chi^{2}=9.74$, $p=0.008$; therefore, the Greenhouse-Geisser adjustment was used. There was a significant main effect across the forms of collaboration, $F(1.95)=476.96$, $p<0.001, \eta_{\mathrm{p}}{ }^{2}=0.57$. Post hoc comparisons indicated that online synchronous collaboration $(M=4.20, \mathrm{SD}=0.94)$ was used significantly more frequently than both in-person collaboration $(M=3.16, \mathrm{SD}=1.30)$ and online asynchronous collaboration $(M=1.84, \mathrm{SD}=0.98)$, and in-person collaboration was used significantly more than online asynchronous collaboration.

With respect to contributing ideas when using these different platforms, participants reported that they often contributed ideas during in-person group discussions $(M=4.03, \mathrm{SD}=0.91)$, sometimes to often contributed ideas to group discussions using online synchronous collaboration $(M=3.58, \mathrm{SD}=0.98)$, and 
Table 1 Summary of multiple regression analysis for in-person group work

\begin{tabular}{lllll}
\hline Variable & $B$ & $\mathrm{SE}_{B}$ & $\beta$ & $p$ \\
\hline Frequency of use & & & & \\
$\quad$ Constant & 1.83 & 0.57 & & 0.001 \\
Extraversion & 0.03 & 0.01 & 0.15 & $0.006^{*}$ \\
$\quad$ Agreeableness & 0.01 & 0.01 & 0.05 & 0.344 \\
Overall effectiveness & & & & \\
Constant & 3.23 & 0.41 & & 0.000 \\
$\quad$ Extraversion & 0.01 & 0.01 & 0.3 & 0.552 \\
Agreeableness & 0.02 & 0.01 & 0.12 & $0.019^{*}$ \\
\hline
\end{tabular}

$B=$ unstandardized regression coefficient; $\mathrm{SE}_{B}=$ standard error of the coefficient; $\beta=$ standardized coefficient

rarely to sometimes contributed ideas when using email $(M=2.43, \mathrm{SD}=1.04)$ or other asynchronous platforms $(M=2.93, \mathrm{SD}=1.10)$.

\section{Personality and experiences with collaborative work}

Two sets of three multiple linear regressions were conducted to determine whether extraversion and agreeableness predicted frequency of use and contribution of ideas for each of the types of collaboration. Increased extraversion significantly predicted how often participants reported meeting in-person with group members to discuss a group assignment, $F(2,357)=4.50, p=0.012$, adj. $R^{2}=0.03$ (see Table 1 for regression coefficients and standard errors) and how often participants used online synchronous collaboration to communicate with group members, $F(2,357)=4.17$, $p=0.016$, adj. $R^{2}=0.02$ (see Table 2 for regression coefficients and standard errors). Neither extraversion nor agreeableness predicted frequency of using asynchronous online collaboration (email) to communicate with group members, $F(2,357)=0.75$, $p=0.471$, adj. $R^{2}=0.004$.

With respect to contribution of ideas within groups, higher levels of both extraversion and agreeableness significantly predicted increased contribution of ideas

Table 2 Summary of multiple regression analysis for online synchronous group work

\begin{tabular}{lrrrl}
\hline Variable & \multicolumn{1}{l}{$B$} & $\mathrm{SE}_{B}$ & \multicolumn{1}{l}{$\beta$} & \multicolumn{1}{l}{$p$} \\
\hline Frequency of use & & & & \\
$\quad$ Constant & 4.26 & 0.41 & & 0.000 \\
Extraversion & 0.02 & 0.01 & 0.13 & $0.015^{*}$ \\
$\quad$ Agreeableness & -0.02 & 0.01 & -0.09 & 0.082 \\
Contribution of ideas & & & & \\
Constant & 2.21 & 0.43 & & 0.000 \\
Extraversion & 0.02 & 0.01 & 0.12 & $0.025^{*}$ \\
Agreeableness & 0.02 & 0.01 & 0.12 & $0.030^{*}$ \\
\hline
\end{tabular}

$B=$ unstandardized regression coefficient; $\mathrm{SE}_{B}=$ standard error of the coefficient; $\beta=$ standardized coefficient 
when using online synchronous collaboration, $F(2,347)=5.45, p=0.005$, adj. $R^{2}=0.03$ (see Table 2 for regression coefficients and standard errors). Neither extraversion nor agreeableness predicted contribution of ideas when using in-person $\left(F(2,299)=2.88, p=0.058\right.$, adj. $\left.R^{2}=0.02\right)$ or asynchronous online collaboration such as email $\left(F(2,357)=0.75, p=0.471\right.$, adj. $\left.R^{2}=0.004\right)$.

\section{Perceived effectiveness of in-person and online collaboration}

To address hypothesis 2, an ANOVA revealed a significant difference in perceived effectiveness among all platforms, $F(2)=100.28, p<0.001, \eta_{\mathrm{p}}{ }^{2}=0.38$. Post hoc comparisons indicated that in-person collaboration $(M=4.17, \mathrm{SD}=0.93)$ was perceived as more effective than both online synchronous $(M=3.76, \mathrm{SD}=1.11)$ and online asynchronous collaboration $(M=2.67, \mathrm{SD}=1.04)$. In addition, online synchronous collaboration was perceived to be significantly more effective than online asynchronous collaboration.

Three multiple linear regressions were conducted to determine whether extraversion and agreeableness predicted perceived effectiveness for each of the methods of collaboration. Perceived effectiveness of in-person collaboration was significantly predicted by increased agreeableness, $F(2,357)=3.10, p=0.05$, adj. $R^{2}=0.02$. Regression coefficients and standard errors can be found in Table 1. Neither extraversion nor agreeableness predicted perceived effectiveness for either synchronous $\left(F(2,357)=1.15, p=0.32\right.$, adj. $\left.R^{2}=0.08\right)$ or asynchronous online collaborations $\left(F(2,357)=1.46, p=0.23\right.$, adj. $\left.R^{2}=0.09\right)$.

\section{Preference for group work as a function of extraversion and agreeableness}

To address hypothesis 3, we assessed whether extraversion and agreeableness impacted preferences for group work, as well as satisfaction with group work using in-person and online collaboration.

\section{Group dynamics and preferences}

Overall, the majority of participants (60\%) preferred the combination of sometimes working in a group and sometimes working on their own compared to only a third $(33.6 \%)$ who preferred to work on their own rather than in a group, and only $6.4 \%$ who preferred to work in a group more than on their own.

Two one-way ANOVAs were conducted to determine if extraversion and agreeableness differed among those who expressed a greater preference for working on their own, working in a group, or equally working in each. There was a significant difference across the three groups as a function of extraversion, $F(2,357)=8.35$, $p<0.001, \eta_{\mathrm{p}}{ }^{2}=0.05$, but no significant differences were found for agreeableness $F(2,357)=2.37, p=0.10, \eta_{\mathrm{p}}{ }^{2}=0.01$. Post hoc comparisons indicated that extraversion scores were lower among participants who preferred to work alone more so than in a group $(M=24.74, \mathrm{SD}=5.22)$ compared to those who expressed an equal 
preference for working alone or in a group $(M=27.24, \mathrm{SD}=5.79)$. No other comparisons were significant.

\section{Satisfaction with group formation}

Students indicated university group formation was equally formed by the instructor $(M=3.08, \mathrm{SD}=1.59)$ and through seeking out classmates or friends with whom they were familiar with $(M=3.56, \mathrm{SD}=1.23)$. Participants indicated that group formation occurred less often through seeking out classmates with whom they were unfamiliar $(M=2.01, \mathrm{SD}=1.03)$. Satisfaction with each of these methods of formation all were above the midpoint of the scale $(M=3.16, \mathrm{SD}=1.04 ; M=3.99$, $\mathrm{SD}=0.90$ and $M=3.26, \mathrm{SD}=0.83$, respectively).

Two multiple linear regressions were conducted to assess whether levels of extraversion and agreeableness predicted frequency of self-determined group selection (i.e., seeking out familiar classmates or seeking out unfamiliar classmates). Neither extraversion nor agreeableness predicted frequency of forming groups by seeking out familiar classmates or friends; however, higher levels of extraversion significantly predicted frequency of forming groups by seeking out unfamiliar classmates, $F(2,357)=3.96, p=0.020$, adj. $R^{2}=0.02$ (see Table 3 for regression coefficients and standard errors).

Three multiple linear regressions were conducted to assess whether levels of extraversion and agreeableness predicted satisfaction with methods of group selection. Higher levels of agreeableness significantly predicted higher levels of satisfaction with groups formed with familiar classmates or friends, $F(2,321)=6.20$, $p=0.002$, adj. $R^{2}=0.04$ (see Table 3 for regression coefficients and standard errors). Neither extraversion nor agreeableness significantly predicted satisfaction with groups formed by an instructor $\left(F(2,258)=1.35, p=0.261\right.$, adj. $\left.R^{2}=0.01\right)$ or satisfaction with groups formed with unfamiliar classmates $(F(2,217)=1.57, p=0.210$, adj. $\left.R^{2}=0.01\right)$.

Table 3 Summary of multiple regression analysis for group work preferences

\begin{tabular}{lcccc}
\hline Variable & $B$ & $\mathrm{SE}_{B}$ & $\beta$ & $p$ \\
\hline $\begin{array}{l}\text { Frequency of seeking } \\
\text { out unfamiliar class- } \\
\text { mates to form groups }\end{array}$ & & & & \\
$\quad$ Constant & 1.63 & 0.45 & & 0.000 \\
Extraversion & 0.03 & 0.01 & 0.015 & $0.006^{*}$ \\
$\quad$ Agreeableness & -0.01 & 0.01 & -0.04 & 0.421 \\
Satisfaction with group & & & & \\
$\quad$ selection with familiar & & & & \\
$\quad$ classmates & & & & 0.000 \\
Constant & 2.61 & 0.42 & & 0.604 \\
Extraversion & 0.01 & 0.01 & 0.29 & $0.001^{*}$ \\
$\quad$ Agreeableness & 0.04 & 0.01 & 0.19 & \\
\hline
\end{tabular}

$B=$ unstandardized regression coefficient $\mathrm{SE}_{B}=$ standard error of the coefficient; $\beta=$ standardized coefficient 


\section{Group-size preferences}

A one-way ANOVA revealed no significant differences in group-size preference (myself and one other person, myself and two others, myself and three others, and myself and four or more others) as a function of either extraversion, $F(3$, $356)=0.72, p=0.542, \eta_{\mathrm{p}}{ }^{2}=0.01$, or agreeableness, $F(3,356)=1.10, p=0.352$, $\eta_{\mathrm{p}}^{2}=0.01$.

\section{Beliefs about group work}

A series of multiple linear regressions were conducted to assess whether beliefs about group work were predicted by extraversion or agreeableness. The regression models for perceived efficiency of group work $(F(2,357)=9.98, p<0.001$, adj. $\left.R^{2}=0.05\right)$, motivation $\left(F(2,357)=14.13, p<0.001\right.$, adj. $\left.R^{2}=0.07\right)$, and satisfaction $\left(F(2,357)=6.76, p<0.001\right.$, adj. $\left.R^{2}=0.04\right)$ were all significant. Higher levels of both extraversion and agreeableness predicted higher belief of efficiency, increased motivation, and higher satisfaction with group work. The overall models for perceived workload $\left(F(2,357)=3.46, p=0.033\right.$, adj. $\left.R^{2}=0.02\right)$ and ability to perform effectively $\left(F(2,357)=7.63, p<0.001\right.$, adj. $\left.R^{2}=0.04\right)$ were significant; however, only higher levels of extraversion predicted a higher belief that working as a member of a group increases one's ability to perform effectively, and only higher levels of agreeableness predicted a decrease in perceived workload. The model for stress level was non-significant across both predictors, $F(2,357)=1.21, p=0.302$, adj. $R^{2}<0.01$. See Table 4 for a full summary.

\section{Preference of platform for academic group work}

To address hypothesis 4, two multiple linear regressions were conducted to assess whether levels of extraversion and agreeableness predicted perceived level of difficulty with generating final output for a group assignment $(M=2.76, \mathrm{SD}=1.21)$, and quality of learning experience $(M=3.29, \mathrm{SD}=1.07)$ when using in-person collaboration compared to online synchronous collaboration. Neither model was significant.

\section{Impact of synchronous group work on social skills}

To address hypothesis 5, two multiple linear regressions were conducted to determine whether extraversion and agreeableness was related to students' ratings of social impact for each of in-person collaboration $(M=3.85, \mathrm{SD}=0.89)$ and online synchronous collaboration $(M=3.43, \mathrm{SD}=0.94)$ contexts. Both models were significant $\left(F(2,357)=5.10, p=0.007\right.$, adj. $R^{2}=0.03$, and $F(2,357)=5.09, p=0.007$, adj. $R^{2}=0.03$, for in-person and online synchronous collaboration, respectively). Within each model, higher levels of extraversion $\left(\beta_{\text {Online }}=0.11\right.$ and $\left.\beta_{\text {In-Person }}=0.12\right)$ and agreeableness $\left(\beta_{\text {Online }}=0.12\right.$ and $\left.\beta_{\text {In-Person }}=0.10\right)$ were associated with more positive social impact (see Table 5 for full summary). 
Table 4 Summary of multiple regression analysis for aspects of group work and extraversion and agreeableness

\begin{tabular}{|c|c|c|c|c|}
\hline Variable & $B$ & $\mathrm{SE}_{B}$ & $\beta$ & $p$ \\
\hline \multicolumn{5}{|l|}{ Efficiency } \\
\hline Constant & 2.07 & 0.32 & & 0.000 \\
\hline Extraversion & 0.03 & 0.01 & 0.19 & $0.026^{*}$ \\
\hline Agreeableness & 0.02 & 0.01 & 0.12 & $0.001 *$ \\
\hline \multicolumn{5}{|l|}{ Motivation } \\
\hline Constant & 1.58 & 0.36 & & 0.000 \\
\hline Extraversion & 0.02 & 0.01 & 0.16 & $0.002 *$ \\
\hline Agreeableness & 0.04 & 0.01 & 0.21 & $0.001 *$ \\
\hline \multicolumn{5}{|l|}{ Satisfaction } \\
\hline Constant & 1.71 & 0.40 & & 0.000 \\
\hline Extraversion & 0.02 & 0.01 & 0.13 & $0.013^{*}$ \\
\hline Agreeableness & 0.03 & 0.01 & 0.13 & $0.024 *$ \\
\hline \multicolumn{5}{|l|}{ Effectiveness } \\
\hline Constant & 1.70 & 0.41 & & 0.000 \\
\hline Extraversion & 0.03 & 0.01 & 0.17 & $0.001 *$ \\
\hline Agreeableness & 0.02 & 0.01 & 0.09 & 0.072 \\
\hline \multicolumn{5}{|l|}{ Workload } \\
\hline Constant & 3.60 & 0.37 & & 0.000 \\
\hline Extraversion & 0.00 & 0.01 & 0.24 & 0.646 \\
\hline Agreeableness & -0.03 & 0.01 & -0.14 & $0.009 *$ \\
\hline \multicolumn{5}{|l|}{ Stress } \\
\hline Constant & 3.69 & 0.46 & & 0.000 \\
\hline Extraversion & -0.01 & -0.01 & -0.05 & 0.297 \\
\hline Agreeableness & -0.01 & 0.01 & 0.06 & 0.292 \\
\hline
\end{tabular}

$B=$ unstandardized regression coefficient; $\mathrm{SE}_{B}=$ standard error of the coefficient; $\beta=$ standardized coefficient

\begin{tabular}{lllll}
\hline Variable & $B$ & $\mathrm{SE}_{B}$ & $\beta$ & $p$ \\
\hline Online synchronous collaboration & & & & \\
$\quad$ Constant & 2.16 & 0.41 & & 0.000 \\
Extraversion & 0.02 & 0.01 & 0.11 & $0.043^{*}$ \\
$\quad$ Agreeableness & 0.02 & 0.01 & 0.12 & $0.023^{*}$ \\
In-Person collaboration & & & & \\
$\quad$ Constant & 2.68 & 0.39 & & 0.000 \\
Extraversion & 0.02 & 0.01 & 0.12 & $0.021^{*}$ \\
Agreeableness & 0.02 & 0.01 & $0.10^{*}$ & $0.047^{*}$ \\
\hline
\end{tabular}

$B=$ unstandardized regression coefficient $\mathrm{SE}_{B}=$ standard error of the coefficient; $\beta=$ standardized coefficient
Table 5 Summary of multiple regression analysis for impact to social skills 


\section{Discussion}

The increasing inclusion of collaborative learning opportunities within higher education contexts, combined with a variety of online and in-person methods for collaboration, necessitates exploration of student perceptions and experiences with these instructional tools. The present study addressed this need with particular attention to the role social skills, particularly extraversion and agreeableness, play in group collaboration contexts (Campion et al. 1993). Two key goals of the present study involved (1) capturing student experiences with different forms of collaboration, and (2) examining the specific impact of extraversion and agreeableness as individual characteristics that could influence a students' learning across different collaboration contexts (in-person, synchronously online, and asynchronously online).

\section{Group structure}

Consistent with pedagogical shifts toward increasing opportunities for group and teamwork experiences in the classroom (e.g., Burke 2011), the majority of students $(60 \%)$ in the present study indicated a preference for a balanced instructional design that provided opportunities for both independent and group work, with a smaller number of students $(6.4 \%)$ preferring group work over independent work when completing assignments. For these students, the inclusion of collaboration opportunities may promote greater learner outcomes and enjoyment (e.g., Laal and Ghodsi 2012). However, for other learners, collaborative formats may pose challenges. In our study, approximately a third of the students identified a preference for working independently on assignments rather than working collaboratively. When preferences were examined in terms of social skills, the preference for independent work was associated with lower levels of extraversion. This outcome aligns with previous literature indicating that individuals high in extraversion experience greater satisfaction and enjoyment (e.g., French and Kottke 2013) and feel more confident in their ability to perform in group work contexts (Barry and Stewart 1997; Thoms et al. 1996; Walker 2007). However, for less socially gregarious students, collaborative learning contexts may be especially challenging and less enjoyable. Although extraversion was related to group work preferences, agreeableness was not. Individuals scoring higher in agreeableness tend to be courteous, helpful, and cooperative (e.g., Farsides and Woodfield 2003) which facilitate the relationship dynamics within groups, whereas extraversion addresses whether individuals seek out and thrive from social stimulation. Thus, it is not surprising that levels of agreeableness did not impact preference for group versus individual work.

Overall, both extraversion and agreeableness predicted positive beliefs about group work such as satisfaction, efficiency, and motivation. In addition, neither personality trait was related to perceived stress as a function of working in a group. Our findings confirm previous research reporting similar positive associations between extraversion and group work variables involving enjoyment and overall group work experience (Walker 2007). Similarly, previous research also indicates a relation 
between agreeableness and satisfaction (French and Kottke 2013). The present study extends these outcomes to an online collaboration context. In addition, given that individuals high in agreeableness function well in social group settings, it would be expected that they would find these settings motivating and efficient. Consistent with previous research, our findings also indicated an association between higher levels of extraversion and the belief that working as a member of a group increased one's ability to perform effectively (Barry and Stewart 1997; Thoms et al. 1996; Walker 2007); however, agreeableness did not predict perception of performance ability. Clearly, individuals high in extraversion would not only seek out opportunities to engage in groups but also rate their participation in groups as a highly positive outcome. This would also appear to be the case for those high in agreeableness but to a slightly lesser degree.

Individuals high in extraversion and agreeableness report these positive perceptions toward group work, suggesting that collaborative instructional techniques might be especially relevant for these individuals. However, recent research suggests that their group members may not concur with these evaluations. Specifically, group members' reports of individuals with high extraversion, and to a lesser extent agreeableness, suggest a curvilinear relationship such that those with average levels of extraversion are perceived to be better team players in a group context than those who are high or low (Curşeu et al. 2019). Together, the current and previous findings suggest that instructors may need to carefully consider the needs of individual students when using collaboration as an instructional tool.

\section{Familiarity with online collaboration tools}

At the outset of the study it was important to determine that participants were sufficiently comfortable with technology and that responses would not be reflecting a lack of comfort with technology. As digital natives (Akçayir et al. 2016), it was not surprising that ratings of comfort with technology approached ceiling levels. However, students did not report uniformly high familiarity ratings across an array of software programs that can be harnessed for collaboration. For example, familiarity ratings for programs such as Google Docs and Google Slides approached ceiling scores, but Prezi and Google+Platforms were less familiar overall and variable across students. Identifying familiarity with technology is a critical first step when choosing and using online collaborative tools as part of instruction as lack of familiarity with technology can hinder use (e.g., Kumar and Vigil 2011).

\section{Experience with in-person, online synchronous, and online asynchronous collaboration}

Given previous literature regarding increased use of technology in higher education contexts (Carrier et al. 2015; Sung et al. 2016), it was expected that students would report use of a variety of online platforms. Students reported that synchronous online and in-person collaboration were more common forms of collaboration relative to asynchronous online formats. Despite the relatively equivalent prevalence 
of in-person and synchronous online collaboration tools, participants believed that in-person collaboration was more effective than online collaboration. While some recent literature has found no notable differences between online and in-person learning modalities in higher education (e.g., Mullen 2020), it appears that collaborating with peers may be a distinguishing factor that contributes to students' preferences for in-person collaboration compared to online. For first-year university students, it appears that there is a disconnect between what is experienced in teaching practice and what they perceive to be most effective. Clearly, in-person group work confers a perceived advantage over online technologies when group work is required.

Comparisons of the two online collaboration methods (i.e., synchronous and asynchronous) indicated greater use and perceived effectiveness for synchronous versus asynchronous collaboration. Similar to in-person contexts, synchronous formats allow students to engage in immediate, real-time interactions with others in the learning process. In part, these perceptions may be fueled by greater engagement in synchronous than asynchronous collaboration formats. Participants indicated that they often contributed ideas when using in-person and online synchronous collaboration formats and rarely contributed ideas when collaborating asynchronously online. Employing collaboration techniques that promote active, engaged learners enhances learning outcomes and enjoyment (e.g., Laal and Ghodsi 2012). Students' indication that they contribute more in synchronous formats (both in-person and online) suggests that working synchronously is more than a social engagement opportunity as it encourages deeper interactions with ideas and knowledge, which are activities known to promote greater learning.

Overall, participants indicated that generating a final output for an academic project was more difficult when using in-person collaboration compared to when using online synchronous collaboration; however, participants reported their learning experiences to be fairly equal across both platforms. The use of online collaboration tools is often prompted by an understanding that students engage in significant work beyond the confines of the classroom (e.g., St. Clair and Tschirhart 2002); thus, the use of online synchronous collaboration may be beneficial for students in higher education when it is difficult to coordinate in-person meetings with group members, or when in-person collaboration is not possible such as online courses, remote teaching, and limited in-class opportunities. It is possible that students believe it is easier to complete a group project using online synchronous collaboration due to conflicting class schedules and differing geographical locations among group members that may make it difficult to arrange an in-person group meeting.

Further, it is possible that students perceive in-person collaboration to be more difficult if they do not all have direct access to the same document as is possible through online synchronous collaboration. During an in-person meeting, only one group member may be the recorder or editor of the document, which may not allow other group members to contribute as effectively as they could if the document could be shared and edited simultaneously online. Consistent with past research (e.g., Shahabadi and Uplane 2015), using online synchronous collaboration seems to be beneficial because it provides similar instant-feedback to in-person collaboration while also maintaining flexibility so that all group members can complete personal 
portions of the group assignment at their leisure, and contribute effectively to the final outcome.

\section{Limitations and future directions}

While our study provides a unique examination of the relations between extraversion and agreeableness and collaborative platforms, both online and in-person, our sample was limited to first-year university students. Students' experiences with these programs may change over their years of study as a function of practice. Future studies should continue to investigate how perceptions of and experiences with group work develop throughout higher education. The present sample also reflected a fairly homogeneous group of participants. Although this sample reflects the first-year population in the university from which they were drawn, in order to generalize the findings more broadly, future studies should assess a more diverse group of students in a university setting.

\section{Implications and conclusions}

Today's modern classroom is a complex environment, and even more so as the COVID-19 pandemic has shifted most higher education to online learning formats (e.g., Chang and Fang 2020; Tesar 2020). Balancing the myriad of instructional tools that can be used within the physical classroom and those that extend beyond the classroom can be challenging when the goal is to meet the needs of all learners. The prevalence and use of online learning tools provides students in higher education contexts with a variety of instructional alternatives to complement traditional in-person activities (e.g., Johnson 2019; Paulsen and McCormick 2020). The present study found that students in first-year university have more experience using both online synchronous and in-person collaboration compared to online asynchronous collaboration. Outcomes such as satisfaction, ability to contribute effectively to the group outcome, and positive beliefs about group work were associated with extraversion and agreeableness and share some important similarities across online synchronous and in-person collaboration contexts. These findings suggest that these two instructional methods may be effective group work tools; however, individual differences in personality impact students' responses to different learning contexts.

The present study was conducted prior to the shift to online learning as a result of the COVID-19 pandemic; thus, the present findings can serve as an important baseline from which to compare findings generated during the pandemic. In addition, the present study provides insights regarding student's perceptions of online collaborative learning which may be particularly salient in these times when online learning is more widespread. The outcomes identify important considerations for educators on how to best integrate collaborative learning in an online setting to acknowledge and accommodate individual differences in personality traits among students. Further research should continue to assess the practical and theoretical implications of individual differences for in-person and online learning for post-secondary students during these changing times. 
Author contributions All authors contributed to study design and development of materials. Recruitment and data collection were completed primarily by HHZ and SP with advice from EW. Data analysis involved MEB and KMB primarily with input from EW. The manuscript was prepared by MEB, KMB, HHZ, and EW with MEB taking the lead role. All authors read and approved the final manuscript.

Funding The authors have no funding sources to declare.

Data availability We did not receive ethics approval for sharing and disseminating data. It was not part of our consent and, therefore, we cannot share the data set.

\section{Compliance with ethical standards}

Competing interests The authors declare that they have no competing interests.

\section{References}

Akçayir M, Dündar H, Akçayir G (2016) What makes you a digital native? Is it enough to be born after 1980? Comput Hum Behav 60:435-440

Alavi M (1994) Computer-mediated collaborative learning: an empirical evaluation. MIS Q 18(2):159-174

Alluri K, Balasubramanian K (2002) Achieving development goals collaboration in education and development. http://pcf4.dec.uwi.edu/collaboration.php

Amichai-Hamburger Y, Wainapel G, Fox S (2004) "On the Internet no one knows I'm an introvert": extroversion, neuroticism, and Internet interaction. Cyberpsychol Behav 5(2):125-128

Apple KJ, Reis-Bergan M, Adams AH, Saunders G (2011) Online tools to promote student collaboration. In: Dunn DS, Wilson JH, Freeman J, Stowell JR (eds) Best practices for technology-enhanced teaching and learning: connecting to psychology in the social sciences. Oxford University Press, Oxford, pp 239-251

Babatunde Adedoyin O, Soykan E (2020) Covid-19 pandemic and online learning: the challenges and opportunities. Interact Learn Environ. https://doi.org/10.1080/10494820.2020.1813180

Bandura A (1978) Social learning theory of aggression. J Commun 28(3):12-29

Bandura A, Walters RH (1977) Social learning theory, vol 1. Prentice-Hall, Englewood Cliffs, N. J

Barrick MR, Mount MK, Judge TA (2001) Personality and performance at the beginning of the new millennium: what do we know and where do we go next? Int J Select Assess 9(1-2):9-30

Barrick MR, Mitchell TR, Stewart GL (2003) Situational and motivational influences on trait-behaviour relationships. In: Barrick MR, Ryan AM (eds) Personality and work: reconsidering the role of personality in organizations. Jossey-Bass, San Francisco, CA, pp 60-82

Barry B, Stewart GL (1997) Composition, process, and performance in self-managed groups: the role of personality. J Appl Psychol 82(1):62-78

Bell ST (2007) Deep-level composition variables as predictors of team performance: a meta-analysis. J Appl Psychol 92:595-615

Benbunan-Fich R, Hiltz SR, Turoff M (2003) A comparative content analysis of face-to-face vs. asynchronous group decision making. Decis Support Syst 34:457-469

Bradley BH, Baur JE, Banford CG, Postlethwaite BE (2013) Team players and collective performance: how agreeableness affects team performance over time. Small Group Res 44(6):680-711

Bruffee KA (1986) Social construction, language, and the authority of knowledge: a bibliographical essay. College Engl 48(8):773-790

Burke A (2011) Group work: how to use groups effectively. J Eff Teach 11(2):87-95

Campion MA, Medsker GJ, Higgs AC (1993) Relations between work group characteristics and effectiveness: Implications for designing effective work groups. Pers Psychol 46(4):823-847

Carrier LM, Rosen LD, Cheever NA, Lim AF (2015) Causes, effects, and practicalities of everyday multitasking. Dev Rev 35:64-78

Chang CL, Fang M (2020) E-learning and online instructions of higher education during the 2019 novel coronavirus diseases (COVID-19) epidemic. J Phys 1574:1-5 
Cohen S, Wills TA (1985) Stress, social support, and the buffering hypothesis. Psychol Bull 98(2):310-357

Colbeck CL, Campbell SE, Bjorklund SA (2000) Grouping in the dark: what college students learn from group projects. J Higher Educ 71(1):60-83

Costa PT, McCrae RR (1992) Normal personality assessment in clinical practice: the NEO Personality Inventory. Psychol Assess 4(1):5-13

Curşeu PL, Ilies R, Vîrgă D, Maricuţoiu L, Sava FA (2019) Personality characteristics that are valued in teams: not always "more is better"? Int J Psychol 54(5):638-649

Driskell JE, Goodwin GF, Salas E, O’Shea PG (2006) What makes a good team player? Personality and team effectiveness. Group Dyn 10(4):249-271

Entwistle NJ, Entwistle D (1970) The relationships between personality, study methods and academic performance. Br J Educ Psychol 40(2):132-143

Farsides T, Woodfield R (2003) Individual differences and undergraudate academic success: the role of personality, intelligence, and application. Personal Individ Differ 34(7):1225-1243

Felder RM, Brent R (2001) Effective strategies for cooperative learning. J Coop Collab College Teach 10(2):69-75

French KA, Kottke JL (2013) Teamwork satisfaction: exploring the multilevel interaction of teamwork interest and group extraversion. Active Learn Higher Educ 14(3):189-200

Furnham A, Chamorro-Premuzic T, McDougall F (2003) Personality, cognitive ability, and beliefs about intelligence as predictors of academic performance. Learn Individ Diff 14(1):47-64

Goby VP (2006) Personality and online/offline choices: MBTI profiles and favored communication modes in a Singapore study. CyberPsychol Behav 9(1):5-13

Gokhale AA (1995) Collaborative learning enhances critical thinking. J Technol Educ 7(1):1-12

Hiltz SR, Benbunan-Fich R (1997) Evaluating the importance of collaborative Learning in ALN's. In Proceedings frontiers in education 1997 27th annual conference teaching and learning in an era of change (Vol. 1, pp 432-436). IEEE

John OP, Srivastava S (1999) The Big Five trait taxonomy: history, measurement, and theoretical perspectives. In: Pervin LA, John OP (eds) Handbook of personality: theory and research. Guilford Press, New York, pp 102-138

Johnson N (2019) Tracking online education in Canadian Universities and Colleges: National Survey of Online and Digital Learning 2019 National Report. Canadian Digital Learning Research Association. https://onlinelearningsurveycanada.ca/publications-2019/

Johnson DW, Johnson RT (1989) Cooperation and competition: theory and research. Interaction Book Company, New York

Johnson DW, Johnson RT, Holubec E, Roy P (1984) Circles of learning: cooperation in the classroom. Association for Supervision and Curriculum Development, Alexandria, VA

Kieser AL, Golden FO (2009) Using online office applications: collaboration tools for learning. Distance Learn 6(1):41-46

Knobel M, Lankshear C (2009) Wikis, digital literacies, and professional growth. J Adolesc Adult Lit 52(7):631-634

Koch MD (2010) Utilizing emergent web-based software tools as an effective method for increasing collaboration and knowledge sharing in collocated student design teams (Unpublished master's thesis). University of Oregon, Eugene, OR

Kopp M, Gröblinger O, Adams S (2019) Five common assumptions that prevent digital transformation at higher education institutions. INTED2019 Proceedings, pp 1448-1457.

Kumar S, Vigil K (2011) The net generation as preservice teachers: transferring familiarity with new technologies to educational environments. J Digit Learn Teach Educ 27(4):144-153

Laal M, Ghodsi SM (2012) Benefits of collaborative learning. Procedia 31:486-490

Lin YT, Chang CH, Hou HT, Wu KC (2016) Exploring the effects of employing Google Docs in collaborative concept mapping on achievement, concept representation, and attitudes. Interact Learn Environ 24(7):1552-1573

Lomas C, Burke M, Page CL (2008) Collaboration tools. Educ Learn Initiat 2(11):1-8

Mahoney JW, Harris-Reeves B (2019) The effects of collaborative testing on higher order thinking: do the bright get brighter? Active Learn Higher Educ 20(1):25-37

McInnerney JM, Roberts TS (2004) Collaborative or cooperative learning? In: Roberts TS (ed) Online collaborative learning: theory and practice. IGI Global, Pennsylvania

Mount MK, Barrick MR, Stewart GL (1998) Five-factor model of personality and performance in jobs involving interpersonal interactions. Hum Perform 11:145-165 
Mullen CA (2020) Does modality matter? A comparison of aspiring leaders' learning online and face-toface. J Further Higher Educ 44:670-688

Myers IB, McCaulley MH (1985) Manual: a guide to the development and use of Myers-Briggs type indicator. Counseling Psychologists Press, Palo Alto, CA

Nieuwoudt JE (2020) Investigating synchronous and asynchronous class attendance as predictors of academic success in online education. Austral J Educ Technol 36(3):15-25

Nyikos M, Hashimoto R (1997) Constructivist theory applied to collaborative learning in teacher education: in search of ZPD. Mod Lang J 81(4):506-517

Offir B, Bezalel R, Barth I (2007) Introvert, extrovert and achievement in distance learning environment. Am J Dist Educ 21(1):3-19

Paulsen J, McCormick AC (2020) Reassessing disparities in online learner student engagement in higher education. Educ Res 49(1):20-29

Resta P, Laferrière T (2007) Technology in support of collaborative learning. Educ Psychol Rev 19(1):65-83

Revelle W, Wilt J (2008) Personality is more than reinforcement sensitivity. Eur J Pers 22(5):407-409

Shahabadi MM, Uplane M (2015) Synchronous and asynchronous e-learning styles and academic performance of e-learners. Procedia 176:129-138

Sharp LA, Whaley B (2018) Wikis as online collaborative learning experiences: "a different kind of brainstorming." Adult Learn 29(3):83-93

Siqin T, van Aalst J, Chu SKW (2015) Fixed group and opportunistic collaboration in a CSCL environment. Int J Comput Support Collab Learn 10(2):161-181

Smith BL, MacGregor JT (1992) What is collaborative learning? In: Goodsell AS et al (eds) Collaborative learning: a sourcebook for higher education. Office of Educational Research and Improvement (ED), Washington, DC, pp 10-30

St. Clair L, Tschirhart M (2002) When and where? Facilitating group work beyond the borders of the classroom. J Manage Educ 26(4):449-461

Sung Y-T, Chang K-E, Liu T-C (2016) The effects of integrating mobile devices with teaching and learning on students' learning performance: a meta-analysis and research synthesis. Comput Educ 94:252-275

Suwantarathip O, Wichadee S (2014) The effects of collaborative writing activity using Google docs on students' writing abilities. Turk Online J Educ Technol 13(2):148-156

Tesar M (2020) Towards a post-Covid-19 “new normality?": physical and social distancing, the move to online and higher education. Policy Fut Educ 18(5):556-559

Thoms P, Moore KS, Scott KS (1996) The relationship between self-efficacy for participating in selfmanaged work groups and the big five personality dimensions. J Org Behav 17(4):349-362

Voorn RJ, Kommers PA (2013) Social media and higher education: Introversion and collaborative learning from the student's perspective. Int J Soc Media Interact Learn Environ 1(1):59-73

Vygotsky L (1978) Interaction between learning and development. Read Dev Child 23(3):34-41

Walker A (2007) Group work in higher education: are introverted students disadvantaged? Psychol Learn Teach 6(1):20-25

Zhou W, Simpson E, Domizi DP (2012) Google Docs in an out-of-class collaborative writing activity. Int J Teach Learn Higher Educ 24(3):359-375 